\title{
Investigación de plasmodium sp en donantes de sangre del Banco de Sangre del Hospital San Felipe
}

\author{
Marcela Celeste Aguilar*, Gina Laitano*
}

\section{RESUMEN}

A nivel mundial se han descrito casos de transmisión de malaria por transfusiones, en Honduras se han reportado 2 casos por transfusión de sangre contaminada con P. falciparum. El método actual para tamizar donantes con riesgo de portar el parásito es la entrevista, y puede mejorar su sensibilidad si se realiza una prueba que permita detectar los verdaderos positivos.

La investigación del antígeno de Plasmodium sp se realizó en 289 donadores del Banco de Sangre del Hospital San Felipe, que previamente aprobaron la entrevista. Se utilizó para la detección del antígeno la prueba rápida de Optimal Diamed y el frotis de gota gruesa.

De los 289 donantes, sólo uno resultó positivo $(0.34 \%)$ en la prueba rápida de Optimal para Plasmodium falciparum, y en la gota gruesa de este donante sólo se observó pigmento malárico. Este donante reside en Tegucigalpa y es originario de Comayagua.

Palabras clave: malaria, donadores de sangre, banco de sangre, entrevista, tamizaje

\section{ABSTRACT}

Malaria transmission cases through transfusions have been described worldwide. In Honduras, two cases through blood transfusion contaminated with P. falciparum have been reported. The current method to diffuse donors with a risk of carrying the parasite is the interview and its sensibility can be improved if a test that allows the detection of the true positives is performed.

A sp Plasmodium antigen investigation was conducted to 289 donors in the Hospital San Felipe's Blood Bank. In order to detect the antigen, the Optimal Diamed quick

"Universidad Nacional Autónoma de Honduras, Facultad de Ciencias, Escuela de Microbiología 
test and the thick drop smear were performed.

Out of 289 donors, in the Optimal Diamed quick test for Plasmodium Falciparum only one was positive $(0.34 \%)$. In this donor's thick drop smear was only observed malarian pigment. This donor resides in Tegucigalpa and is originally from Comayagua.

Key words: malaria, blood donors, blood bank, interview, diffuse 


\section{INTRODUCCIÓN}

La malaria o paludismo es la enfermedad parasitaria más importante del mundo porque causa un número de muertes superior a la de cualquier otra enfermedad transmisible.

Es un grave problema de salud pública en más de 90 países con una prevalencia de 300 - 500 millones de casos clínicos anuales, por lo cual tiene un enorme impacto socioeconómico y el $40 \%$ de la población está en riesgo de contraerla. La mortalidad es de aproximadamente 1-2 millones de muertes cada año, la mayoría ocurre en niños pequeños en especial en las áreas rurales remotas con poco acceso a la asistencia médica. Más del $90 \%$ de la carga de morbilidad mundial por malaria está en África Subsahariana.

Varios factores influyen en el aumento anual de la prevalencia de malaria, entre ellos la creación de nuevos sitios de crianza para los mosquitos por la construcción, deforestación, proyectos de irrigación, nuevas prácticas en la agricultura y los cambios en el medio ambiente que alteran el ecosistema. También, la migración de la población de áreas con malaria a áreas libres de malaria tiende a producir una alta frecuencia de transmisión. Otros factores son el costo de los programas de prevención y control, la resistencia de los mosquitos a los insecticidas y la resistencia del parasito Plamodium falciparum a drogas son graves problemas en países en desarrollo con alta prevalencia de la enfermedad.

En Honduras, la malaria está entre las principales causas de morbilidad y continúa siendo un problema de salud pública, principalmente en las zonas rurales más vulnerables de la zona atlántica del país, donde la pobreza obliga a las personas a habitar viviendas desprotegidas. Además, las personas viven sin acceso a los servicios básicos como agua potable, alcantarillado sanitario, sistemas de canalización e infraestructura para el manejo de aguas estancadas. Su importancia no sólo tiene que ver con la cantidad de casos al año, sino con los efectos secundarios como el ausentismo laboral y escolar, así como pérdidas en las empresas y familias.

Los departamentos de Colón y Atlántida históricamente han reportado alta incidencia de malaria, tanto por Plasmodium vivax y P.falciparum. En el 2007, las regiones departamentales de mayor riesgo de malaria fueron: Gracias a Dios, 4,265 casos ( $43 \%$ del total nacional); Colón, 1,552 casos (16\%); Olancho, 1,125 casos (11\%); Atlántida, 602 casos (6\%) e Islas de la Bahía 444 casos (5\%). Estas regiones acumulan el $81 \%$ de la malaria de todo el país. 
Se han descrito casos de transmisión de malaria a través de la transfusión de productos sanguíneos. En un estudio realizado en Estados Unidos sobre los casos de malaria transmitidos por transfusiones, un 35\% fueron debidos a Plasmodium falciparum, un $27 \%$ a Plasmodium vivax, un $27 \%$ a Plasmodium malariae, un $3 \%$ a Plasmodium ovale y un $2 \%$ a especies no identificadas. La mortalidad de los casos de malaria asociada a transfusiones es alrededor del $11 \%$, siendo los principales factores de riesgo la edad y la infección por Plasmodium falciparum.

En Honduras, se han reportado 2 casos de malaria por transfusión de sangre contaminada con $P$. falciparum, de los cuales uno fue fatal:

1. El primer caso se reportó en abril de 2006 en una niña de 17 meses de edad hospitalizada en el Hospital Escuela, quien desarrolló malaria por Plasmodium falciparum y murió. Fue referida del Hospital San Francisco de Olancho y hospitalizada el 17 de marzo debido a sangrado gastrointestinal bajo, secundario a anemia con hemoglobina de $4.8 \mathrm{gr}$. / dl. La paciente recibió tres transfusiones de sangre los días 16 y 17 de marzo y 4 de abril y desarrolló fiebre el 6 de abril. Después se le identificó $P$. falciparum en examen por gota gruesa. La paciente murió el 9 de abril. Se entrevistó y examinó la familia y los donantes de sangre y se extrajo ADN de los plasmas de los donantes. Se realizó la técnica de PCR con marcadores moleculares polimórficos (Bloque II del gene MSP1 de $P$. falciparum) para comparar los parásitos del donador implicado y la paciente. Se realizó búsqueda activa de casos entre los familiares y vecinos del paciente (Guanaco) del donador implicado (Patuca). Exámenes de gota gruesa de 21 familiares y vecinos fueron negativos. El donador del Hospital San Francisco fue asintomático y positivo con 8 gametocitos en cien campos. Otros donadores fueron negativos. Entre 35 familiares y vecinos del donador implicado, se detectó otro caso asintomático. Además un niño de 3 meses de edad recibió sangre del donador positivo y presentó palidez y febrícula. Éste fue diagnosticado con infección por $P$. falciparum. Al realizar el PCR la paciente y el donador presentaron el mismo patrón.

2. El segundo caso se reportó en una mujer de 64 años de edad, la cual fue hospitalizada en el Hospital Escuela el 26 de agosto de 2008 y se le diagnosticó malaria por Plasmodium falciparum. Se le identificó la transfusión sanguínea como posible origen de su malaria, ya que la paciente no residía ni había visitado zonas endémicas, pero fue transfundida dos semanas antes de hospitalizarse. Con el apoyo de la Dirección General de Vigilancia de la Salud de la Secretaría de Salud y la Cruz Roja Hondureña se trazaron cinco donantes, los cuales se estudiaron por PCR pero el análisis microscópico y biológico molecular no identificó infección por $P$. falciparum en los sujetos referidos como donadores. 
Entre las posibles causas para no amplificar ADN de las muestras de los donadores: 1. Los donantes son portadores asintomáticos con parasitemias muy bajas para ser detectadas. 2. Posibilidad de eliminación de los parásitos por ingesta de antimaláricos. 3. No había infección por $P$. falciparum. Se recomendó que las muestras sean analizadas en otro laboratorio para confirmar los resultados.

\section{OBJETIVO GENERAL}

Conocer la prevalencia de malaria en los donantes de sangre del Banco de Sangre del Hospital San Felipe en el período de julio de 2008 a enero de 2009.

\section{OBJETIVOS ESPECÍFICOS}

1. Comparar la utilidad de la prueba rápida de Optimal Diamed para investigar malaria con la gota gruesa.

2. Determinar la prevalencia en porcentaje de malaria en donantes de sangre del Banco de Sangre del Hospital San Felipe.

3. Clasificar las muestras positivas por malaria de acuerdo a la procedencia de los donantes y a la especie de parásito.

\section{RESULTADOS}

Participaron en el estudio 289 donantes que asistieron al Banco de Sangre del Hospital San Felipe, de los cuales la mayor parte fueron hombres 235 (81.31\%) y 54 (18.68\%) fueron mujeres (cuadro $\mathrm{N}^{\circ} 1$ ).

Cuadro $N^{\circ}$ 1. Características Sociodemográficas de los Donantes Estudiados en el Banco de Sangre del Hospital San Felipe de julio de 2008 a enero de 2009

\begin{tabular}{|c|c|c|} 
Característica & $\begin{array}{c}\text { Donantes } \\
\text { mujeres }\end{array}$ & $\begin{array}{c}\text { Donantes } \\
\text { hombres }\end{array}$ \\
\cline { 2 - 3 } & \multicolumn{2}{|c|}{ Edad (años) } \\
\hline Rango & $23-44$ & $18-65$ \\
\hline Media & 36 & 32 \\
\hline Total & 54 & 235 \\
\hline
\end{tabular}


En el cuadro $\mathrm{N}^{\circ} 2$ se presentan los departamentos de procedencia de los donantes estudiados, observándose que el mayor porcentaje proceden del departamento de Francisco Morazán (67.82\%), de los cuales 161 fueron hombres y 35 mujeres.

Los departamentos de Lempira, Atlántida y Santa Bárbara presentan el menor porcentaje de procedencia de donantes con $0.34 \%$ cada uno.

Cuadro $\mathrm{N}^{\circ}$ 2. Departamento de Procedencia de los Donantes Estudiados en el Banco de Sangre del Hospital San Felipe de julio de 2008 a enero de 2009

\begin{tabular}{|c|c|c|c|c|c|}
\hline \multirow{2}{*}{$\begin{array}{c}\text { Departamento de } \\
\text { procedencia }\end{array}$} & \multicolumn{2}{|c|}{ Donantes } & \multirow{2}{*}{$\begin{array}{l}\text { Departamento de } \\
\text { procedencia }\end{array}$} & \multicolumn{2}{|c|}{ Donantes } \\
\hline & Mujeres & Hombres & & Mujeres & Hombres \\
\hline Francisco Morazán & & & Valle & & \\
\hline Tegucigalpa & 28 & 139 & Nacahome & 2 & 1 \\
\hline Talanga & 2 & 4 & San Lorenzo & & 1 \\
\hline Reitoca & & 1 & Amapala & & 2 \\
\hline Sabanagrande & & 2 & Goascorán & 1 & \\
\hline Tatumbla & & 2 & Olancho & 3 & 7 \\
\hline San Juan de Flores & & 1 & Juticalpa & & 4 \\
\hline Mateo & & 1 & Santa Cruz & & 1 \\
\hline Santa Ana & & 2 & Colón & & 2 \\
\hline Santa Cruz & 1 & & Tocoa & & 1 \\
\hline Río Abajo & & 1 & Limón & & 1 \\
\hline Amarateca & & 1 & Lempira & & 1 \\
\hline Zamorano & & 1 & Comayagua & 4 & 4 \\
\hline Santa Lucía & 1 & 1 & Taulabé & & 1 \\
\hline San Matías & & 1 & La Libertad & & 4 \\
\hline Valle de Ángeles & & 1 & Siguatepeque & & 3 \\
\hline Cedros & 1 & 1 & Rosario & & 1 \\
\hline Orica & 1 & & Intibucá & 1 & \\
\hline Ojojona & & 2 & La Esperanza & 1 & \\
\hline Güaimaca & 1 & & Yamaranguila & & 1 \\
\hline Choluteca & 1 & 14 & Yoro & & \\
\hline San Marcos de Colón & & 2 & El Progreso & & 1 \\
\hline Pespire & & 2 & Olanchito & 2 & \\
\hline $\begin{array}{l}\text { La Paz } \\
\text { El Paraíso }\end{array}$ & $\begin{array}{l}1 \\
1\end{array}$ & $\begin{array}{l}3 \\
5\end{array}$ & $\begin{array}{l}\text { Ocotepeque } \\
\text { Cortés }\end{array}$ & & \\
\hline San Antonio de & & 1 & San Pedro Sula & & 1 \\
\hline Oriente & & & Cofradía & & 2 \\
\hline Danlí & 1 & 3 & Atlántida & & \\
\hline Güinope & 1 & & Tela & & 1 \\
\hline Nicaragua & 1 & & Santa Bárbara & 1 & \\
\hline
\end{tabular}


De acuerdo con la entrevista realizada a cada donante, las áreas más visitadas por éstos fueron Tegucigalpa (112) y le siguen Choluteca (8), Olancho (7), Comayagua (5), Cortés (5) y Atlántida (4). Las áreas menos visitadas por los donantes fueron Valle, Lempira y La Paz (cuadro $\mathrm{N}^{\circ} 3$ ).

Cuadro $\mathrm{N}^{\circ}$ 3. Áreas visitadas con mayor frecuencia por los donantes de Sangre del Hospital San Felipe de julio de 2008 a enero de 2009

\begin{tabular}{|l|c|}
\hline \multicolumn{1}{|c|}{ Área visitada } & Donantes \\
\hline Tegucigalpa & 112 \\
\hline Atlántida & \\
\hline La Ceiba & 3 \\
\hline Tela & 1 \\
\hline Comayagua & 5 \\
\hline Choluteca & 8 \\
\hline Cortés & 1 \\
\hline San Pedro Sula & 4 \\
\hline Cofradía & 1 \\
\hline Olancho & 6 \\
\hline Catacamas & 1 \\
\hline Lempira & 1 \\
\hline La Paz & 1 \\
\hline El Paraíso & 2 \\
\hline Danlí & 1 \\
\hline Yoro & \\
\hline Olanchito & 2 \\
\hline Valle & 1 \\
\hline Nacaome & 148 \\
\hline No viajó & \\
\hline
\end{tabular}

Del total de donantes sólo uno (0.34\%) fue positivo para Plasmodium falciparum en la prueba rápida y en gota gruesa. El donante reside en Tegucigalpa pero en la entrevista únicamente refiere ser originario de Comayagua.

En la gota gruesa de este donante se observó solamente pigmento malárico y la prueba rápida de Optimal resulto débilmente positiva. La incidencia teórica obtenida por 1,000 donantes es de 3.4. 


\section{CONCLUSIONES}

1. Se encontró solamente un donante positivo (0.34\%) por Plasmodium falciparum, el cual reside en Tegucigalpa que es una zona de baja transmisión de malaria.

2. De acuerdo a estos resultados preliminares se sugiere la opción de incluir en las pruebas de tamizaje de donantes la realización de una prueba rápida para diagnóstico de malaria en especial en áreas endémicas, que permita excluir la posibilidad de aceptar a donantes portadores de malaria y de esta manera prevenir la malaria por transfusión.

3. Los resultados demuestran que se encontró positividad en donantes que aprobaron la entrevista, lo cual deja ver la necesidad de hacer más rigurosa la entrevista previa a la donación.

4. La prueba de diagnóstico rápido de Optimal para tamizar malaria, en comparación con la gota gruesa resulto sensible y especifica en la detección del parásito, aun con sólo la presencia del pigmento malárico que se observó en la gota gruesa del donante positivo. Esto evidencia que la coloración de la banda obtenida en la prueba rápida está en proporción directa al número de parásitos.

5. En los bancos de sangre de nuestro país, la entrevista es el método estándar actual para tamizar donantes potenciales con riesgo de portar el parásito que produce la malaria y puede mejorar su sensibilidad si se realiza una prueba que permita detectar los verdaderos positivos y así evitar excluir a donantes potenciales.

6. Actualmente la exclusión de un donante por riesgo de transmitir malaria se basa en la permanencia en una zona endémica, lo cual puede ser un criterio no suficiente para prevenir la malaria transmitida por transfusión, ya que el estado de portador puede extenderse desde varios meses a varios años.

7. Es necesario hacer énfasis durante la entrevista al donante potencial el registro de antecedentes epidemiológicos como que el donante resida en zonas endémicas o haya visitado áreas endémicas, antecedentes de haber padecido malaria, si recibió tratamiento, especie de Plasmodium y si completó el tratamiento.

8. Se recomienda extender esta investigación en donadores de bancos de sangre de áreas endémicas para malaria.

\section{COMENTARIOS}

El donante que resultó positivo por Plasmodium falciparum posteriormente será reconfirmado con una tercera prueba. 


\section{AGRADECIMIENTOS}

Al personal del Banco de Sangre del Hospital San Felipe, donde se realizó este estudio, por su apoyo y colaboración especialmente a la jefa del Banco de Sangre, Dra. Lourdes Morales. A Edna Urbina, estudiante del Internado Rotatorio de la carrera de Microbiología, por la ayuda técnica que nos brindó.

\section{BIBLIOGRAFÍA}

Asociación Americana de Bancos de Sangre. Manual Técnico. 15ª edición. Bethesda, Maryland. 2007.

Arrospide V, Nancy, Puray C, Maritza, Guzmán S, Elisa et al. Uso de pruebas rápidas inmunocromatográficas para la detección de Plasmodium falciparum en donantes de sangre en Perú. Rev. Perú Med exp. Salud Pública, abr/jun 2004. Vol.21, $\mathrm{N}^{\circ} 2, \mathrm{p} .76-81$.

Bleje, Jorgelina, Carreras Vescio, Luis, Salamone, Horacio. Riesgo de transmisión de infecciones por vía transfusional. Buenos Aires. Medicina. 2,002. Vol. 62, Nº 3, p. 259-278.

Castillo, Carmen M y Ramírez, Carolina. Tamización de malaria en donantes de sangre en Calí, Colombia. Biomédica. Junio 2,005. Vol. 25, № 2, p. 203-210.

Centro para el Control y Prevención de Enfermedades (CDC). Malaria: Blood Donor Screening. Atlanta. Febrero 2009.

Fondo Mundial para la lucha contra el SIDA, tuberculosis y malaria y Ministerio de Salud Pública de Nicaragua. Utilidad de la prueba de diagnóstico rápido para malaria "Optimal" en 13 municipios de alta transmisión de P. falciparum. Nicaragua abril a junio 2004.

Organización Mundial de la Salud. Informe mundial sobre el paludismo. Ginebra. 2005.

Radillo, Alfredo. Medicina Transfusional. Editorial Prado. México D.F. 2006. 